\title{
Co-Extrusion of Zr Lined $U$-Zr Alloy Characterization Report
}

Nuclear Technology

Research and Development

Prepared for

U.S. Department of Energy Advanced Fuels Campaign Randall Fielding, Brady Mackowiak, Ginger Dexter, and Blair Grover Idaho National Laboratory

31 January 2018 NTRD-FUEL-2018-000081 



\section{DISCLAIMER}

This information was prepared as an account of work sponsored by an agency of the U.S. Government. Neither the U.S. Government nor any agency thereof, nor any of their employees, makes any warranty, expressed or implied, or assumes any legal liability or responsibility for the accuracy, completeness, or usefulness, of any information, apparatus, product, or process disclosed, or represents that its use would not infringe privately owned rights. References herein to any specific commercial product, process, or service by trade name, trade mark, manufacturer, or otherwise, does not necessarily constitute or imply its endorsement, recommendation, or favoring by the U.S. Government or any agency thereof. The views and opinions of authors expressed herein do not necessarily state or reflect those of the U.S. Government or any agency thereof. 



\section{SUMMARY}

A feasibility study was undertaken to assess the feasibility of co-extruding U$10 \mathrm{Zr}$ and U-6Zr with a zirconium barrier on the outside surface. A U-10Zr and U-6Zr billet were cast, machined, and sealed in a zirconium can. The can was extruded with an extrusion ratio of approximately 35.5. After extrusion the extruded rods were sectioned for easier handling, radiographed, and examined metallographically. Radiography showed the rods to be solid with the exception of one location in the U-6Zr rod. Metallography showed the expected deformed microstructure in the longitudinal direction, although this was much less noticeable in the U-6Zr structure. Also seen in the microstructure of both rods was a zirconium gradient; the zirconium concentration was higher near the zirconium liner as compared to the interior of the rod. Based on the successful completion of these experiments, co-extrusion of U-Zr alloys with a zirconium liner is feasible. 



\section{CO-EXTRUSION OF ZR LINED U-ZR ALLOY CHARACTERIZATION REPORT}

\section{INTRODUCTION}

The Advanced Fuels Campaign (AFC) is tasked with the development of fabrication techniques for novel fuel forms and compositions while maintaining the goal of less than $0.1 \%$ unrecoverable losses. Transmutation fuels fabricated during the AFC and previous programs were produced though casting, usually arc casting. However, it is well known that arc casting cannot be scaled to a commercial-scale, tens of kilograms, or likely even the engineering-scale of a few kilograms. Previously, EBR-II fuel was also cast using an inductively heated counter gravity injection casting technique. This method of fabrication worked well for the solid EBR-II fuel, and was originally selected based on its ability to be performed remotely in a hot cell environment. Although casting was shown to be an efficient manner in which to produce fuels, there are other possible methods that should also be examined. One method that has been used in the past for fuel fabrication is extrusion. Extruded fuels were used in EBR-I and in other reactors since then; however, most of these reactors used a lower melting point fuel composition compared to current fuel compositions of interest. None used uranium-zirconium (U-Zr) alloy fuel, which is currently the reference composition of current interest to the advanced fuel community. Although casting has been used to produce much of the recent U-Zr alloy fuel, extrusions may also have advantages such as increased batch yields, fewer molds, good dimensional control, and the ability to produce fuels with more complex cross sections.

Extrusion is the process where a billet of larger diameter is forced through a die of reduced cross section. Extrusion can be done either hot or cold depending on the material, although uranium and U-Zr alloys are done hot. Extrusion is ideally suited for shapes with a long aspect ratio and consistent cross sectional area. As annular fuel forms are further developed, a consistent and scalable fabrication process is needed. Casting of annular fuel has proven to be very difficult in the past because of the long aspect ratios of the fuel; therefore, extrusion may be an ideal method of fabricating this form using the uranium alloys of interest. An additional benefit of extrusion is the possibility of co-extruding a barrier material on the outside of the fuel at the same time as the fuel is extruded. Some of the previously extruded fuels were coextruded with the cladding. For the purposes of this study the barrier material serves as a diffusion barrier between the fuel fission product and the cladding, mitigating fuel cladding chemical interaction (FCCI), and therefore should be substantially thinner than what was previously performed.

This report details the characterization of a recent feasibility test to determine if uranium-10wt\% zirconium (U-10Zr) and uranium-6wt\% zirconium (U-6Zr) can be successfully co-extruded with a zirconium liner or can. Both U-10Zr and U-6Zr billets were cast and seal welded into a close fitting zirconium can. After canning the billets both were extruded and characterized. Characterization included radiographic examination, dimensional inspection, and metallography of radial and longitudinal samples along the length of the extrusion. A third U-10Zr billet was cast directly into the zirconium can; however, this billet has not yet been extruded.

\section{EXPERIMENTAL}

Two zirconium cans were machined from grade 702 zirconium. Figure 1 shows a sketch of the seal welded can. The outside diameter of each can was $1.35 \mathrm{in} .(34.29 \mathrm{~mm})$ and the inside diameter of each can was 1.125 in. $(28.58 \mathrm{~mm})$ resulting in a wall thickness of $0.1125 \mathrm{in}$. $(2.86 \mathrm{~mm})$. Both cans were $3.576 \mathrm{in}$. (3.58 mm) long. These dimensions correspond to the standard dimensions of an uncanned billet for extrusion. While the cans were being fabricated, U-6Zr and U-10Zr billets were cast using vacuum induction melting. The crucible was loaded with sheared zirconium sheet pieces and machine turnings on the bottom, followed by depleted uranium rods, approximately $0.3 \mathrm{in}$. $(7.6 \mathrm{~mm})$ in diameter of various lengths. Table 1 shows the mass of material used for each billet and the resulting cast product. Despite the 
differences in compositions, both billets were cast using the same heating profile as shown in Figure 2 . The crucible was heated and held at $1500^{\circ} \mathrm{C}$ for approximately 43 minutes to allow the zirconium to fully dissolve and the molten material was then poured into the mold. After casting, the billets were machined to the appropriate length for extrusion and the diameter was reduced to allow a slip fit into the zirconium can with minimum clearance. The billet sketch in Figure 3 shows the nominal dimensions of the billet. It should be noted that no attempt has been made to optimize the casting process to reduce the amount of scrap material made. After machining and test fitting to final dimensions the billets were loaded and seal welded in the zirconium cans. Sealing was done in a purified argon atmosphere glovebox using standard gas tungsten arc welding techniques. After welding the billets were ready for the extrusion process.

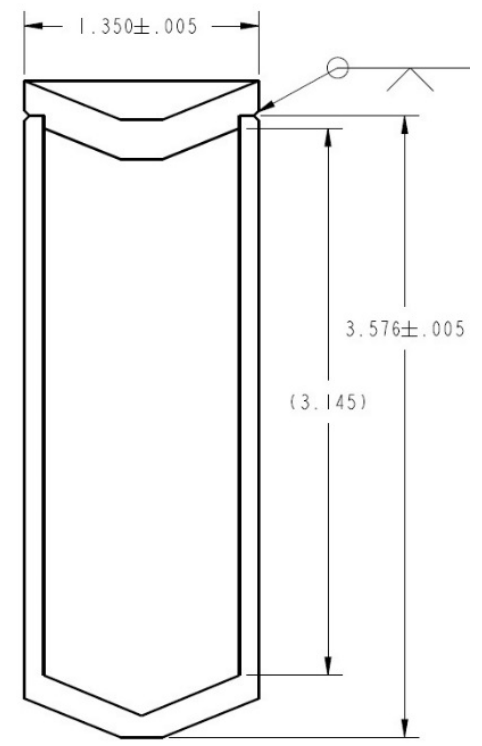

Figure 1. Zirconium can assembly, leading end is up and trailing end (footer) is down. Dimensions shown are in inches.

Table 1. U-10Zr and U-6Zr billet information.

\begin{tabular}{|c|c|c|}
\hline & U-6Zr & U-10Zr \\
\hline Loaded U (g) & 2177.67 & 2193.43 \\
\hline Loaded Zr (g) & 139.16 & 244.60 \\
\hline As Cast Billet (g) & 2211.94 & 2300.79 \\
\hline Dross* (g) & 104.89 & 137.24 \\
\hline \multicolumn{3}{|c|}{$\begin{array}{l}\text { *- Dross includes any material that did not drain from the crucible. } \\
\text { Dross mass is calculated based on the difference between total mass } \\
\text { charged and as cast billet mass. }\end{array}$} \\
\hline
\end{tabular}




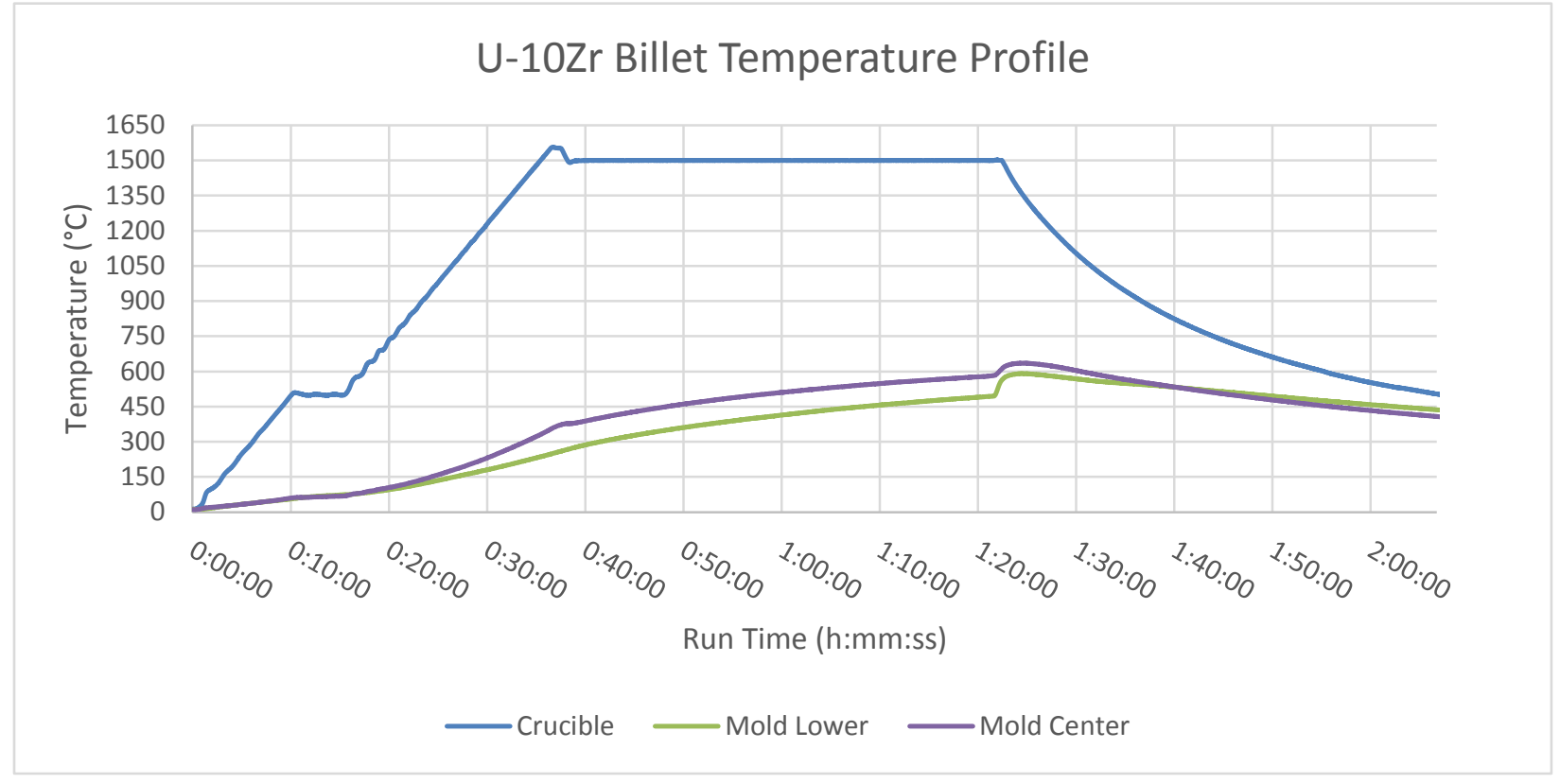

Figure 2. Typical heating profile for the U-Zr billets.

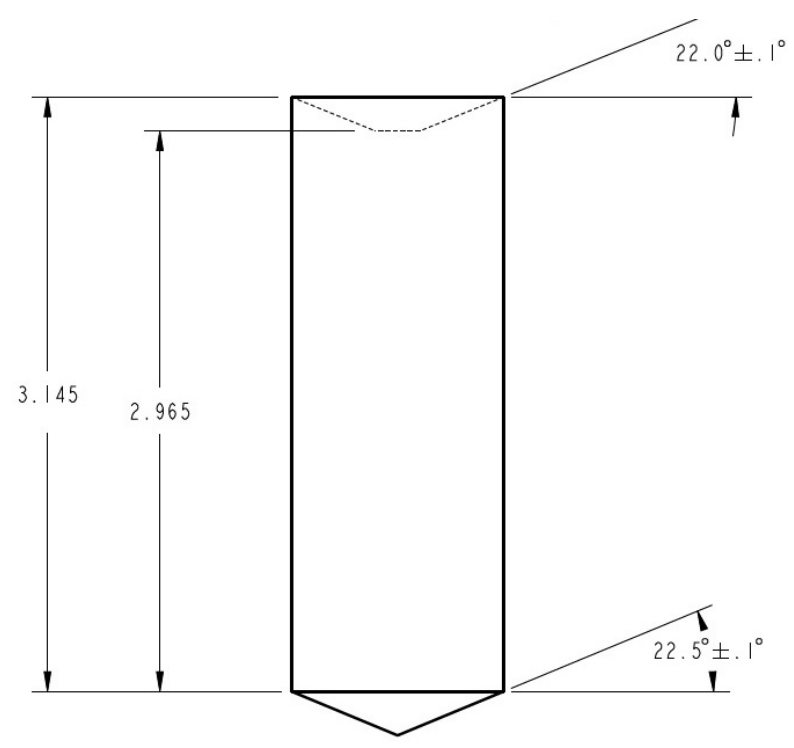

Figure 3. Sketch of the final machined billet ready for canning. As with Figure 1 the footer or trailing end is down on the sketch. Dimensions are in inches.

Both billets were extruded at INL on the 120 ton extrusion press line, using the same extrusion and heating parameters. Billets and copper headers and footers were heated in a salt bath at $800^{\circ} \mathrm{C}$ for 30 minutes. After removal from the salt the billets were immediately transferred to the extrusion press and the extrusion operation began. The total time between removal from the salt to extrusion was approximately 20 seconds. Tooling of the extrusion press was heated to $450^{\circ} \mathrm{C}$ for approximately 30 minutes and loaded into the press just prior to billet removal from the salt. During extrusion the extrusion ram speed was set at 38 inches/minute. An argon purge was applied to the extruded rod upon exiting from the die. It should be noted that the U-6Zr billet was inadvertently loaded and extruded backwards, i.e. 
footer first. After extrusion each extruded rod was sectioned into approximately $10 \mathrm{in}$. (254 mm) long segments for ease of handling. After sectioning, the rods were radiographed to determine if any large voids were present, visually and dimensionally inspected, and microstructurally characterized.

\section{RESULTS}

All casting and extrusion went as planned. Table 2 provides dimensional and mass data for billets in both the as cast and as machined condition. Figure 4 shows the billet and $\mathrm{Zr}$ can prior to seal welding. After welding, the can was stacked with a copper header and footer Figure 5 shows the material ready for extrusion. It was noted during seal welding that the U-6Zr billet fit well and welded smoothly with no observable billet movement inside the can. In contrast, the U-10Zr billet did not fit quite as well in the $\mathrm{Zr}$ can resulting in the presences of a small gap in the weld area that was filled during welding. After welding a small amount of movement could be felt inside of the zirconium can. Despite the questionable fit, extrusion was performed as planned. Extrusion was uneventful with one exception being the U-6Zr billet was inadvertently loaded into the press backwards, footer first. The U-6Zr billet was extruded first, followed by the U-10Zr billet. In the time between extrusions the tooling was re-heated to $400-450^{\circ} \mathrm{C}$. Figure 6 shows the center portion of the extruded U-6Zr product. The surface on both extruded rods was somewhat variable ranging from a smooth surface to a much rougher surface with a gritty or scaly finish, possibly due to retained salt, lubricant, or oxidation. During extrusion the main ram and mandrel force and speed is monitored. Based on these forces the extrusion coefficient was calculated based on Equation 1 below where $\mathrm{F}$ is the force needed to perform the extrusion and $\mathrm{k}$ is the extrusion coefficient:

$$
\text { Eq 1. } F=k A_{o} \ln \frac{A_{o}}{A_{f}}
$$

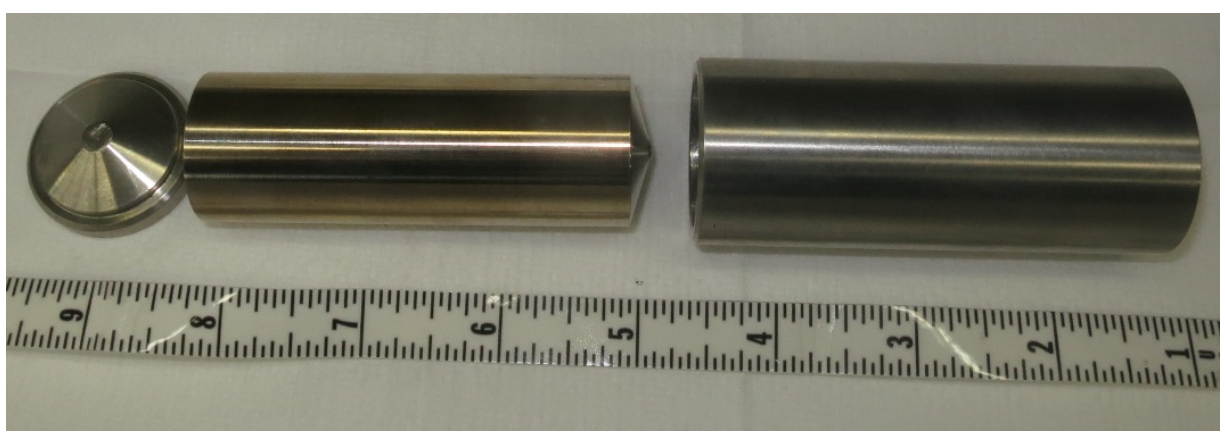

Figure 4. U-6Zr billet and copper can stack, ready for assembly and welding. 


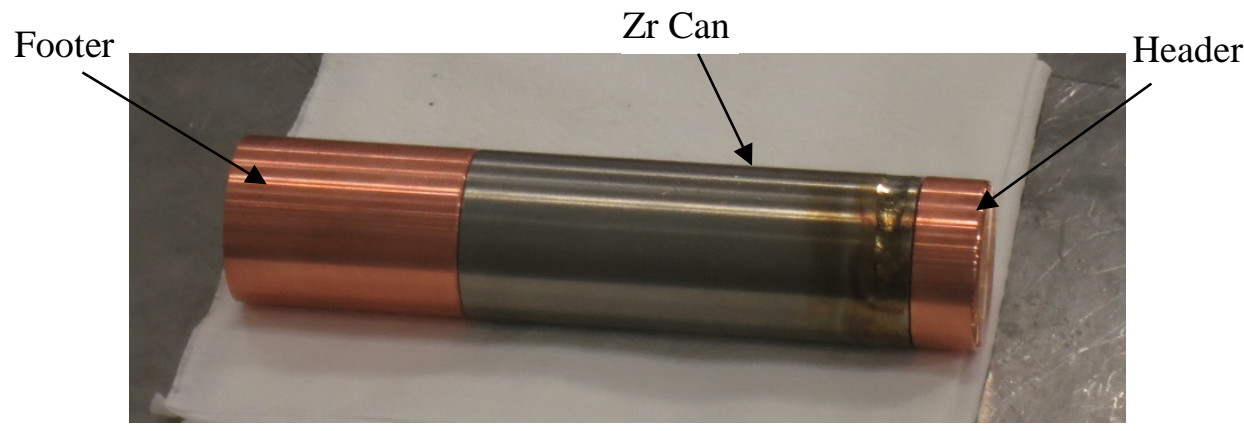

Figure 5. U-10Zr can with header and footer.

Table 3 shows total upset force, the upset force at approximately 3 inches along the billet extrusion, and the peak force as well as the corresponding extrusion coefficient seen during the extrusion for each billet. Appendix I contains the annotated force and velocity profile for each extrusion.

Table 2. Resulting billet mass and dimensions.

\begin{tabular}{|c|c|c|c|c|c|c|}
\hline \multirow{2}{*}{} & \multicolumn{3}{|c|}{ As Cast } & \multicolumn{3}{c|}{ As Machined } \\
\cline { 2 - 7 } & Mass (g) & Length* (mm) & Dia (mm) & Mass (g) & Length (mm) & Dia (mm) \\
\hline U-6Zr & 2211.94 & 112.7 & 36.9 & 852.66 & 95.8 & 34.3 \\
\hline U-10Zr & 2300.79 & 124.5 & 37.1 & 811.81 & 96.3 & 34.5 \\
\hline
\end{tabular}

*- Length is based on length from bottom of billet to the approximate level top, discounting shrinkage.

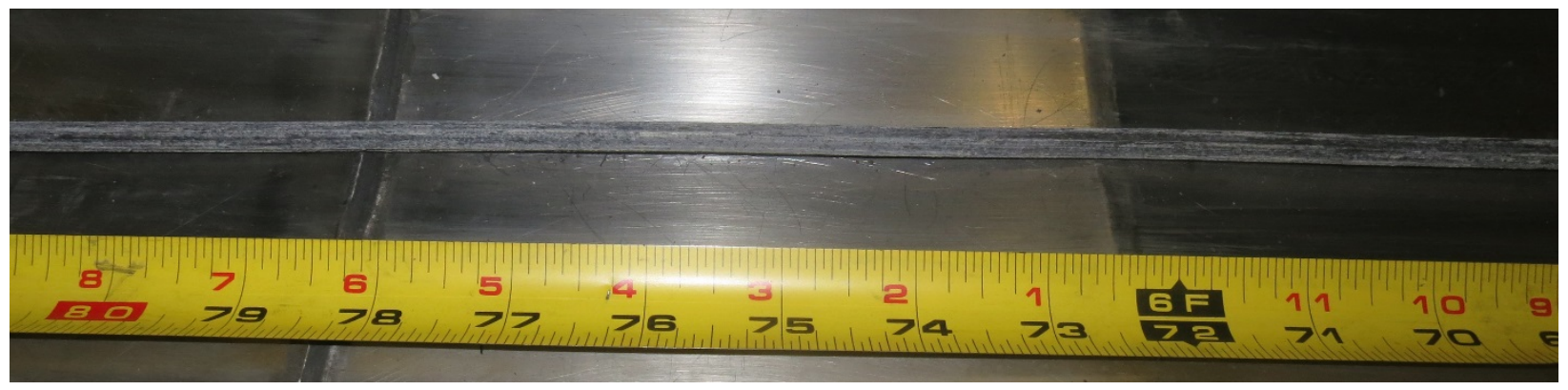

Figure 6. Center portion of extruded U-6Zr.

Table 3. Resulting force and corresponding extrusion coefficients.

\begin{tabular}{|c|c|c|c|c|c|c|}
\hline & $\begin{array}{c}\text { Total Upset } \\
\text { Force (tons) }\end{array}$ & $\begin{array}{c}\text { Upset extrusion } \\
\text { coefficient (ksi) }\end{array}$ & $\begin{array}{c}3 \text { in. Force } \\
\text { (tons) }\end{array}$ & $\begin{array}{c}\mathbf{3} \text { in. extrusion } \\
\text { coefficient (ksi) }\end{array}$ & $\begin{array}{c}\text { Peak } \\
\text { extrusion } \\
\text { Force (tons) }\end{array}$ & $\begin{array}{c}\text { Peak extrusion } \\
\text { coefficient (ksi) }\end{array}$ \\
\hline $\mathbf{U}-6 Z r$ & 91.2 & 32.2 & 88.9 & 31.4 & 106.7 & 37.7 \\
\hline $\mathbf{U}-10 Z \mathbf{Z}$ & 100.6 & 35.6 & 97.2 & 34.3 & 109.5 & 38.7 \\
\hline
\end{tabular}


For ease of handling after extrusion both rods were cut into approximately $10 \mathrm{in}$. (250 mm) lengths. Following sectioning the rods were radiographed using x-ray radiography. Radiography showed the bulk of the pins to be solid with no visible porosity; although, some low density (higher brightness) indications were seen at points along the length of both compositions. The fuel zone starting and ending points were quite different from the two different compositions. The U-6Zr showed a much more tapered fuel starting than the U-10Zr rod. The fuel ending points were also quite different. There was a large void at the fuel zone end of the U-6Zr rod. There were also what appeared to be fuel streaks or smears along the length. This is in contrast to the abrupt end of the U-10Zr fuel rods which showed no transitions to the end of the rod. Figure 7 shows the fuel starting and ending areas of each composition. This is consistent with the visual observations seen during extrusion. During extrusion a break was observed at the fuel to footer transition and it was assumed that this was caused by separation of the footer from the canned fuel rod. Based on measurements made on the radiographic images, the zirconium thickness was approximately $0.020 \mathrm{in}$. $(0.5 \mathrm{~mm})$. Also based on the radiographic images, several areas were chosen for further metallographic analysis. Sample locations were determined from radiographic images and were taken from the tapered beginning, approximately $160 \mathrm{~mm}$ past the fuel beginning, approximate center area, and at the very end and over the void. From each sample area both a radial and longitudinal section were taken. Areas of interest were similar in the U-10Zr composition. Samples were taken from the fuel zone start, approximately $80 \mathrm{~mm}$ into the fuel zone, the approximate center, and near the fuel zone end. During fuel sectioning a more detailed examination of the rods was possible. Immediately noticeable was deep grooving of the fuel along the length. Each composition had irregular grooves or scratches which spiraled along the length of the fuel; however, there were no obvious areas lacking zirconium cover. Radiological scans of the samples also revealed no radiological contamination. Dimensions of each rod were taken. The diameter of each initially sectioned rod was taken at the approximate center of each piece. Two measurements were made approximately $90^{\circ}$ apart from each other. Resulting measurements are shown in Table 4.
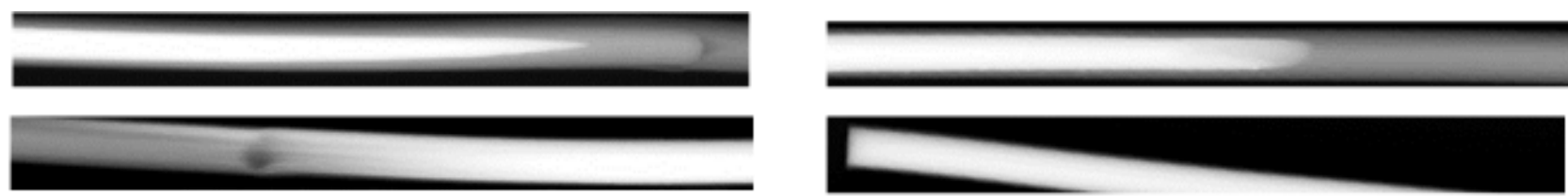

Figure 7- Top Left) U-6Zr fuel zone beginning Lower Left) $\mathrm{U}-6 \mathrm{Zr}$ fuel zone end Top Right) U-10Zr fuel zone beginning Lower Right) $\mathrm{U}-10 \mathrm{Zr}$ abrupt fuel zone end 
Table 4. Dimensional summary of the extruded rods.

\begin{tabular}{|c|c|c|c|c|c|c|c|}
\hline U-6Zr & $\begin{array}{c}\text { Length } \\
\text { (mm) }\end{array}$ & $\begin{array}{l}\text { Dia-1 } \\
(\mathrm{mm})\end{array}$ & $\begin{array}{l}\text { Dia-2 } \\
(\mathrm{mm})\end{array}$ & $\begin{array}{c}\mathrm{U}- \\
10 \mathrm{Zr}\end{array}$ & $\begin{array}{c}\text { Length } \\
\text { (mm) }\end{array}$ & $\begin{array}{l}\text { Dia-1 } \\
\text { (mm) }\end{array}$ & $\begin{array}{l}\text { Dia-2 } \\
\text { (mm) }\end{array}$ \\
\hline 1 & 241.3 & 6.27 & 6.53 & 1 & 249.2 & 6.03 & 5.91 \\
\hline 2 & 250.8 & 6.07 & 5.34 & 2 & 252.4 & 5.94 & 5.77 \\
\hline 3 & 250.8 & 5.66 & 6.21 & 3 & 252.4 & 5.74 & 5.87 \\
\hline 4 & 250.8 & 6.19 & 5.73 & 4 & 250.8 & 6.1 & 6.3 \\
\hline 5 & 250.8 & 6.44 & 5.95 & 5 & 250.8 & 6.08 & 6.23 \\
\hline 6 & 250.8 & 6.09 & 6.3 & 6 & 254.0 & 6.62 & 5.59 \\
\hline 7 & 250.8 & 6.72 & 6.03 & 7 & 252.4 & 6.14 & 5.85 \\
\hline 8 & 250.8 & 6.19 & 6.02 & 8 & 252.4 & 5.5 & 5.66 \\
\hline 9 & 247.7 & 6.14 & 6.02 & 9 & 254.0 & 5.57 & 5.63 \\
\hline 10 & 250.8 & 6.53 & 5.96 & 10 & 252.4 & 5.65 & 5.57 \\
\hline 11 & 247.7 & 6.49 & 6.1 & 11 & 252.4 & 5.77 & 5.93 \\
\hline 12 & 249.2 & 6.03 & 6.49 & 12 & 241.3 & 5.32 & 5.53 \\
\hline 13 & 225.4 & 5.93 & 5.74 & & & & \\
\hline
\end{tabular}

\subsection{Metallography Results}

\subsubsection{U-6Zr Microstructure}

Longitudinal and radial sections were examined from the center portion of the U-6Zr rod. Examination of the radial section showed a microstructure similar to what was expected. Liner thickness was estimated to be between $500 \mu \mathrm{m}-600 \mu \mathrm{m}$, because of the high surface roughness exact measurements made at various locations varied within this range. The microstructure was a typical 3 phase microstructure composed of fine distributions of $\alpha$-uranium and $\delta$ - $\mathrm{UZr}_{2}$, and larger high zirconium precipitates throughout the structure. Figure 8 shows a typical radial micrograph. Also observed was a microstructural gradient from the $\mathrm{Zr}$ liner to the interior of the rod. Figure 9 shows an example of this. The liner and bulk fuel appear to be bonded with a small amount of porosity being visible on the interface line. However, also notable is the noticeably courser microstructure next to the liner. Energy dispersive x-ray spectroscopy (EDS) scans revealed that the area of courser microstructure was several percent high higher in zirconium than the interior. EDS data shows that the gradient does not appear to be uniform, with decreasing uniformly towards the center of the fuel, but rather appears to have a more abrupt drop in zirconium content, as it moves away from the liner. The longitudinal center sample showed very similar microstructure, as seen in Figure 10-11. 


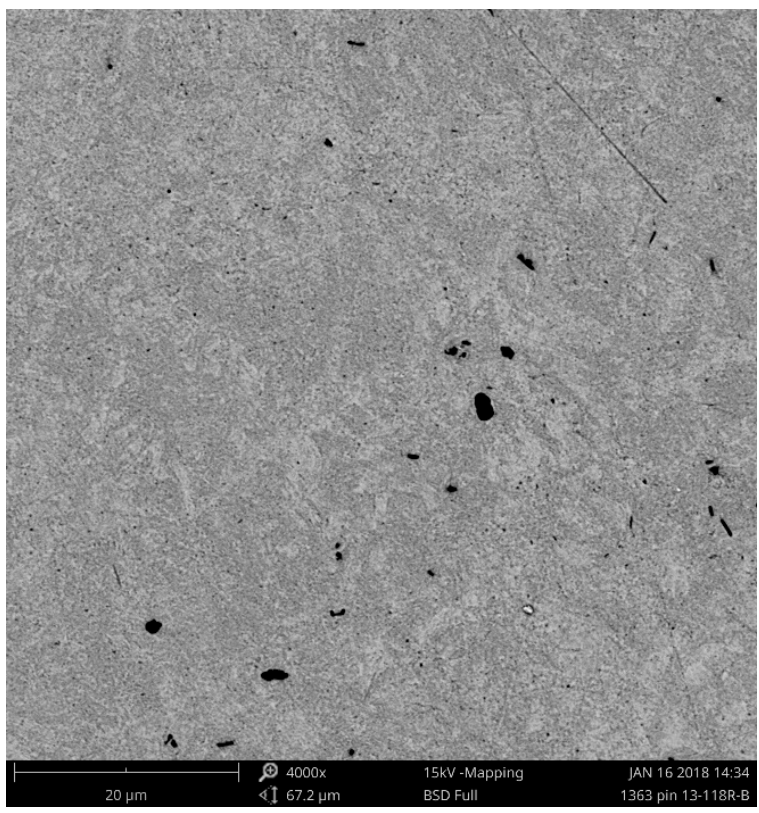

Figure 8. Typical interior microstructure consisting of $\alpha$ (lighter) phase, $\delta$ (darker) phase, and zirconium precipitates (black phase).

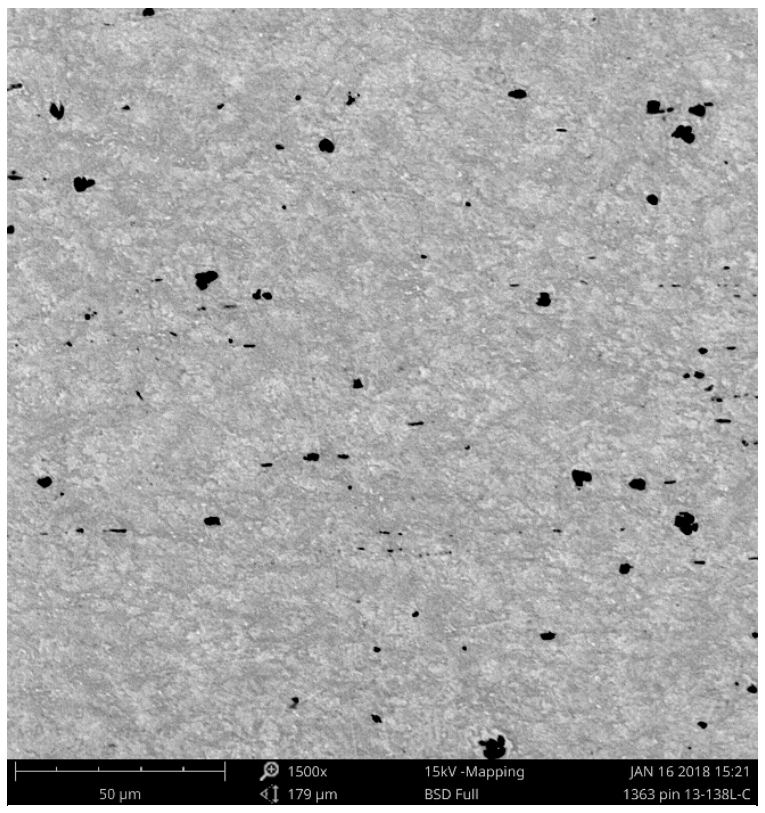

Figure 10. U-6Zr interior rod longitudinal view.

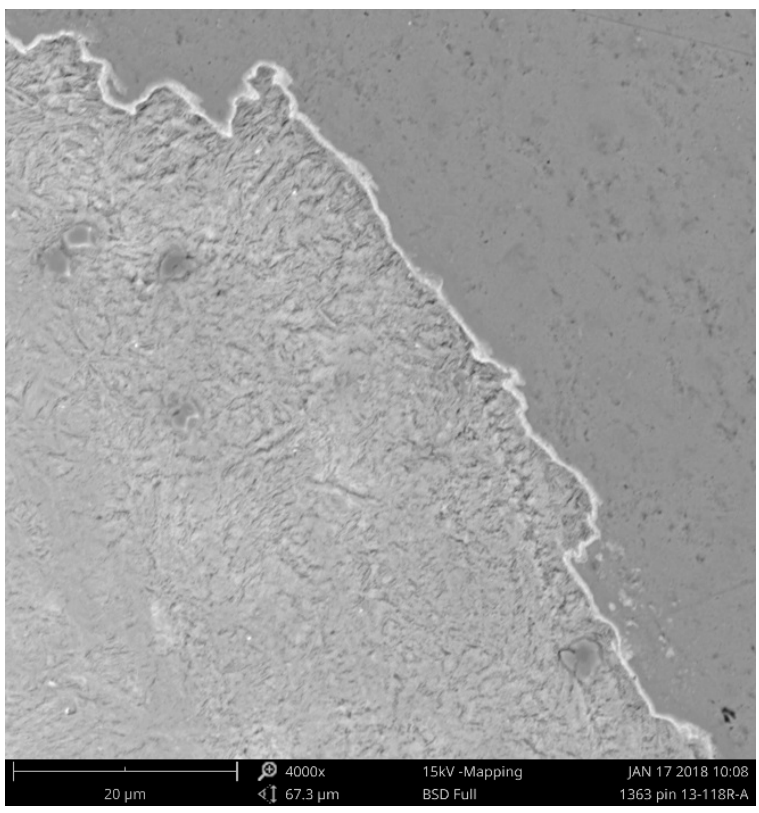

Figure 9. Edge microstructure showing courser phase near the $\mathrm{Zr}$ liner progressing to a finer microstructure.

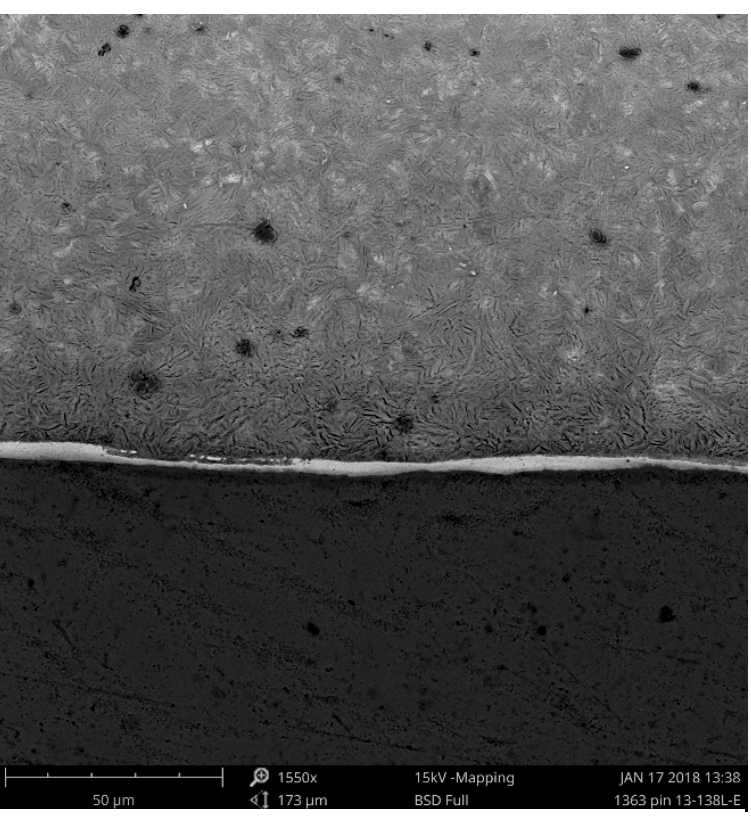

Figure 11. U-6Zr Rod edge longitudinal view. Dark area on lower portion is the $\mathrm{Zr}$ liner.

Leading and tailing ends of the extruded product had similar microstructures in the fuel regions; however, there was a transition zone between the copper header/footer, leading/tailing ends of the zirconium can, 
and the fueled region. It can be clearly seen in Figure 7that the leading end was quite tapered. This piece was sectioned and the resulting microstructure is shown in Figure 12. Figure 12 shows the copper outer layer extruded over the zirconium can, and a thick zirconium region surrounding a tapered fuel region. Also shown at the beginning of the tapered region are several large voids. Based on the radiographic images it appears that within 50-100 mm the fuel region is essentially uniform, with some irregularities in shape due to the surface roughness.

The trailing end was also examined. The general fuel microstructure appears consistent the length of the rod however, like the leading end, the shape of the fueled region was not consistent. As shown in Figure 7 a large void developed at the end of the fueled region. The radiographic image of the trailing end also appeared to show uranium streaking. This area was sectioned and found to be an area where the copper footer material had flowed into the fuel section during extrusion. Because the fuel total thickness was reduced by the copper flowing through it the radiographic images appeared as streaks. Figure 13 shows a radial image where the copper was visible surrounded by fuel alloy.

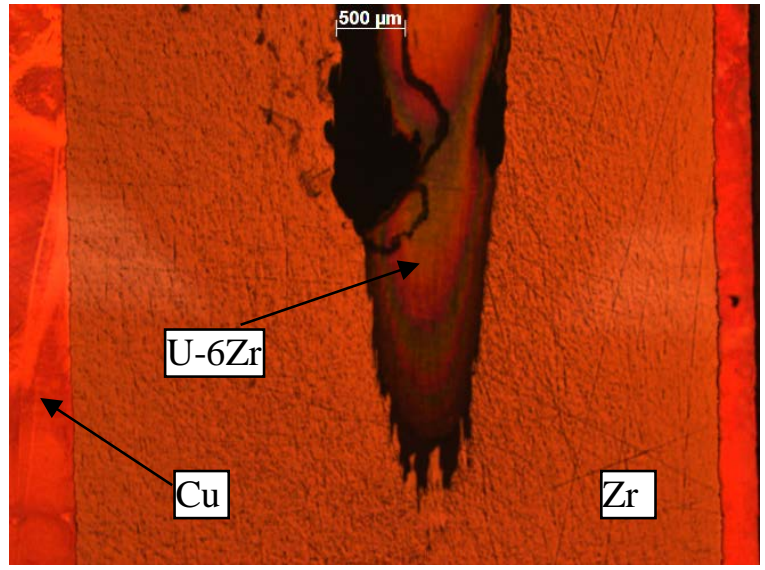

Figure 13. Leading end of the extrusion showing the tapered fuel section.

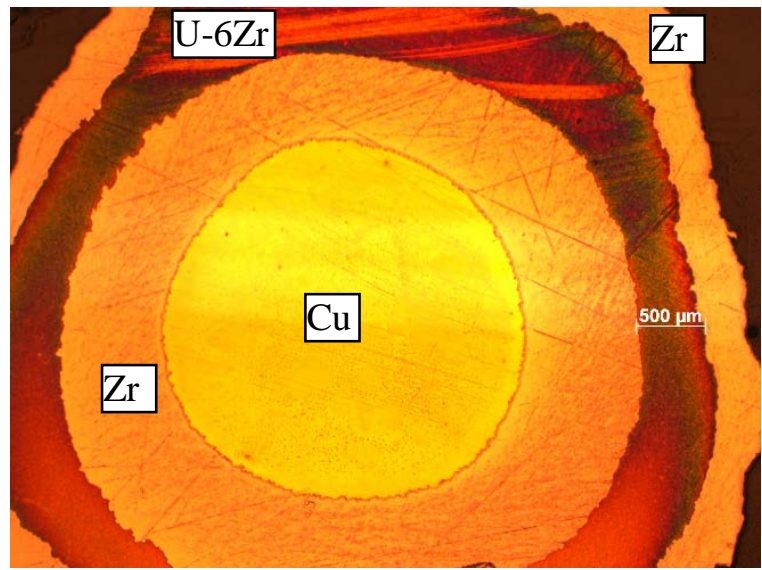

Figure 14. Trailing end of the extrusion. 


\subsubsection{U-10Zr Microstructure}

Extrusion of the U-10Zr rod went as planned and was very similar to the U-6Zr extrusion. As seen in Table 4 the average diameter of the U-10Zr rod was slightly smaller than that of the U-6Zr. The Zr liner was also slightly thinner. As with the U-6Zr rod, a consistent Zr thickness measurement was not possible because of the roughness of the extruded product. However, based on estimates made from metallographic images, the $\mathrm{Zr}$ liner thickness is slightly less (approximately $50 \mu \mathrm{m}$ ) than the $\mathrm{Zr}$ liner present on the U-6Zr rod. The central section microstructure was similar to the U-6Zr, a mixture of $\alpha$ uranium, $\delta \mathrm{UZr}_{2}$, and $\mathrm{Zr}$ precipitates. This is also typical of what is seen in U-10Zr fuels, as shown in Figures 15. Based on optical microscopy a grain size of approximately $20 \mu \mathrm{m}$ or less can be visually estimated. Different from the U-6Zr rod, however, the longitudinal view shows a deformed microstructure with well aligned zirconium precipitates, shown in Figure 16.

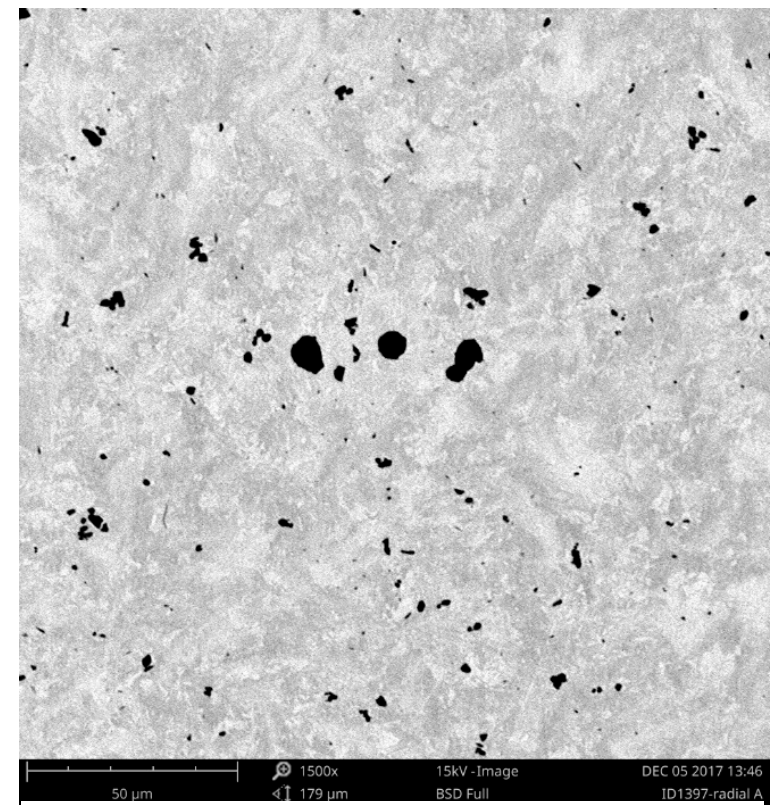

Figure 15. Radial section from the center portion of the U-10Zr rod.

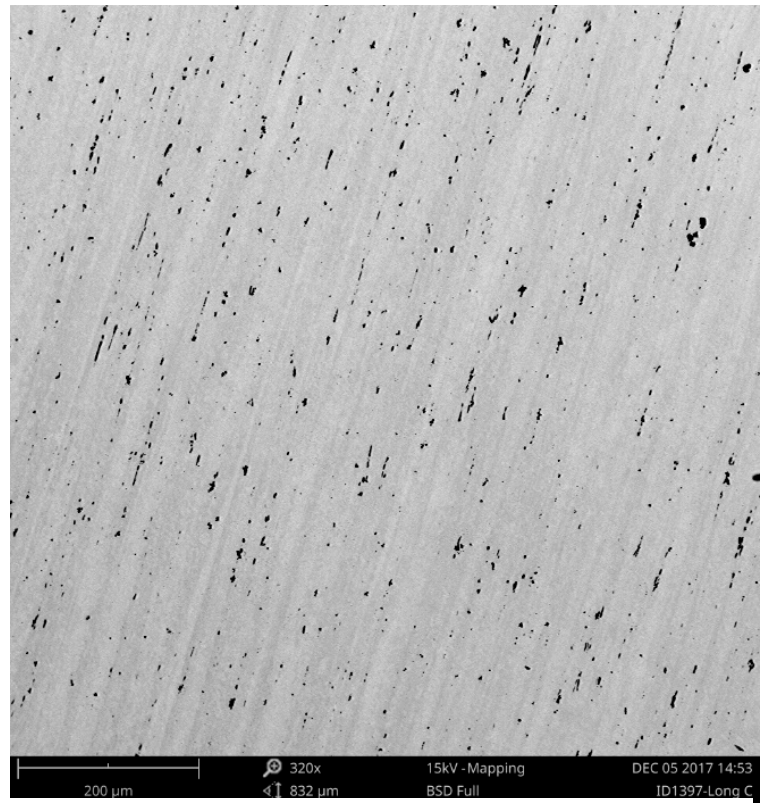

Figure 16. Longitudinal section from the center portion of the U-10Zr rod.

Similar to the U-6Zr extrusion a zirconium and microstructure gradient can be seen along the length of the fuel with a lower zirconium content towards the inside of the fuel. EDS analysis showed this gradient to be slightly greater than the gradient seen in the U-6Zr fuel. Figure 17 shows an x-ray map near the outside edge on the trailing end of the rod which illustrates the gradient well. Unlike the U-6Zr fuel the trailing end of the U-10Zr ended abruptly. This can be seen in Figure 7, as well as metallographic analysis. Samples taken from the trailing end were very similar to those taken from the center of the fuel but the leading end was different. Although the fuel did not appear as tapered, a small taper was still visible. The start of the fuel zone appeared with a blunted end. On the very end of the fuel a decrease in density can be detected on the radiograph. This length was sectioned and showed some zirconium flowed into the interior of the rod before the fuel reached a steady state flow. Figure 18 shows a radial cut section with zirconium present in the center and on the outside surfaces. As with the U-6Zr extrusion the steady state flow was reached with $100 \mathrm{~mm}$ or less. 

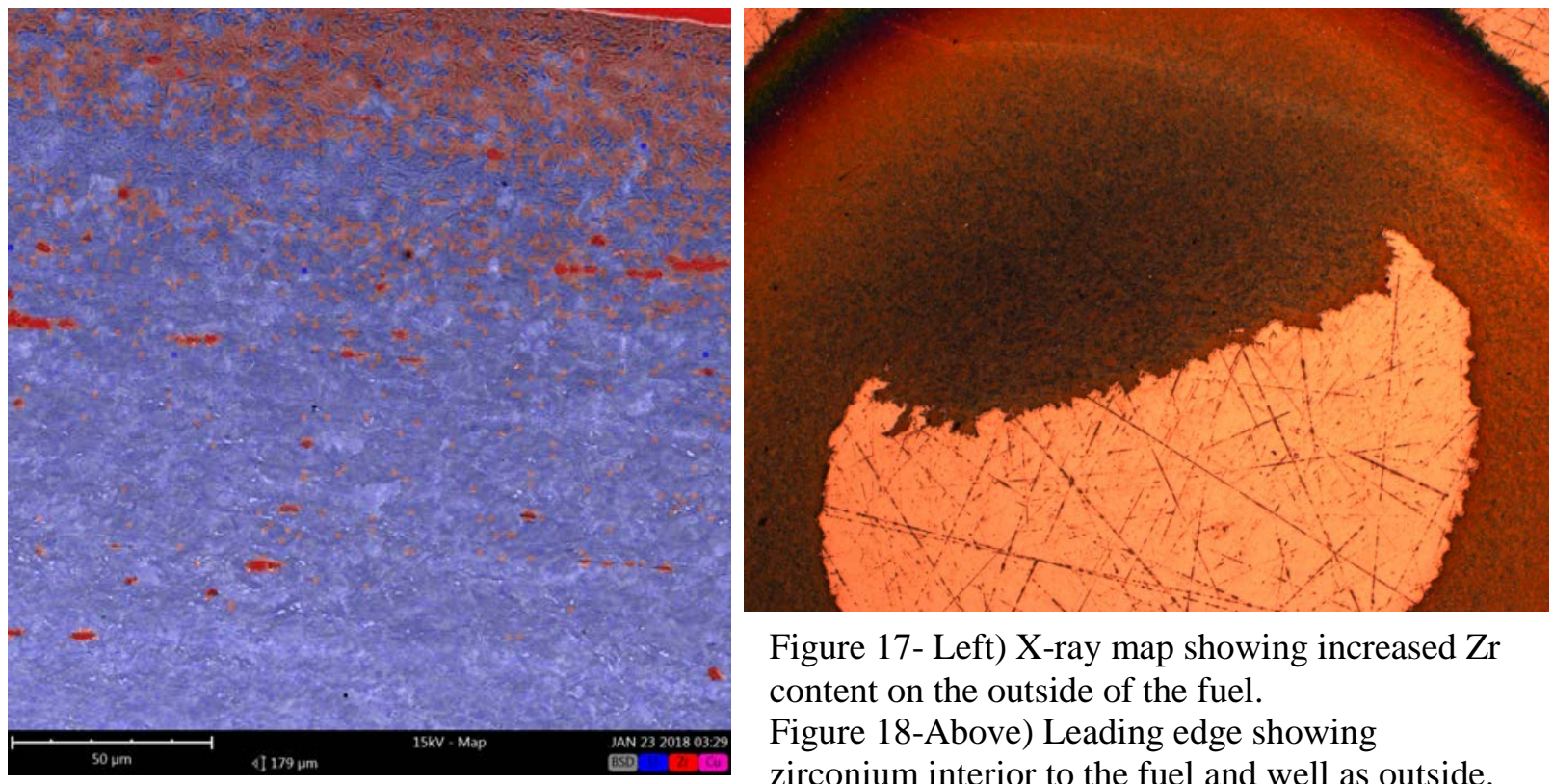

Figure 17- Left) X-ray map showing increased Zr content on the outside of the fuel.

Figure 18-Above) Leading edge showing zirconium interior to the fuel and well as outside.

\section{CONCLUSION/DISCUSSION}

This work has shown the feasibility of co-extruding zirconium canned U-6Zr and U-10Zr, although work remains to optimize the process and determine the operating envelope. Optimizing the operating envelope may lead to a more efficient process; i.e. less waste, less force needed for extrusion, dimensional consistency, etc. The first item to note was the very rough surface finish of both rods. The surface finish was caused by well-worn and grooved dies. The current work was seen as a feasibility test only, and therefore new dies were not obtained. Also, because this was a feasibility test the final liner thickness was not optimized. As discussed above, because of the grooved surface a definitive diameter is not possible, however, if it is assumed that the final diameter was $6.05 \mathrm{~mm}$ (nominal die dimension), the nominal diameter of the extrusion die, then based on the reduction ratio of the entire can assembly, the liner thickness would be approximately $0.5 \mathrm{~mm}$. This is consistent with the measured thickness of the liner. This shows that the zirconium alloy extrudes very similarly to the uranium alloy. The liner thickness of $\mathrm{U}-10 \mathrm{Zr}$ was slightly less than that of the U-6Zr suggesting that $\mathrm{U}-10 \mathrm{Zr}$ is slightly harder, as would be expected with the increased amount of $\delta$-phase present. Both rods appeared to be fully lined with zirconium. Although the $0.5 \mathrm{~mm}$ is much thicker than a FCCI barrier warrants, this thickness can be reduced by reducing the wall thickness of zirconium can.

The U-6Zr had a much more pronounced taper at the leading edge of the fuel zone, and a much more complex microstructure at the trailing end with zirconium and copper flowing into the center of the extruded rod. As discussed in the experimental section, the U-6Zr assembly was inadvertently loaded in the press backwards, i.e. "footer" first. Because the footer used a similar taper as the extrusion die, when the billet assembly was loaded the footer (now the header) fit well with the die. As the extrusion initiated the material in the center of the billet, behind the die opening extruded much easier because it was not constrained and therefore started to extruded before the bulk of the billet had flowed into the die opening. Because the center portion extruded slightly more than the rest of the material the taper on the machined uranium billet was enhanced during extrusion. The trailing end of the fuel was also influenced by the inadvertent loading. During extrusion the flow in the die should be smooth and somewhat laminar after the initial transition of the upset is complete. This laminar flow continues until the end of the extrusion when a more turbulent flow is induced by the stem, or ram, pushing all of the material out of the die. The copper footer has been designed to be substantially longer than the leading header, to allow all of the 
billet to be extruded before this turbulent end region is reached. However, in the case of the U-6Zr billet, what became the footer was not long enough, and the turbulent die clean out portion of the extrusion initiated before the canned assembly was fully extruded. This is in contrast to the U-10Zr assembly. Although some tapering and inconsistencies were noted on the leading end, the trailing end ended abruptly with no visible sign of turbulent flow. The leading edge, although less tapered than that seen in the U-6Zr assembly, still showed signs of flow inconsistencies evidenced by zirconium in the interior of the rod. However, based on the radiographic images and metallography the flow of material became more laminar and regular within the first $100 \mathrm{~mm}$ of the extruded rod. A remedy of this would likely be to increase the length of the copper header to allow the material to reach laminar flow before the billet assembly is extruded.

Both U-6Zr and U-10Zr showed a zirconium gradient from higher zirconium content on the outside edge and lower zirconium content in the center. From initial characterization, the gradient does not appear to be a uniform decrease through the thickness. Figure 17 shows a more abrupt drop from the higher content to lower. It should be noted however, that this gradient has not been fully characterized yet. The cause of the gradient is under investigation. It is possible that the hot extrusion process enhances diffusion from the zirconium can to the interior, however, the assembly is only heated for approximately 30 minutes and the extrusion is performed quickly, and then is cooled. Another possible cause of the gradient is zirconium segregation in the starting billet. This possibility is also being investigated by performing metallography on the initial billet; however, this is still in progress.

In conclusion, this work has shown that co-extrusion of a zirconium lined uranium-zirconium fuel is feasible and within the capabilities of currently available equipment. Although feasible, there are several areas where future work is possible. The first area of improvement is a repeat of this study using a new die. Use of a new die will allow for better characterization of the dimensional stability of the extrusion process. As mentioned above, the initial billets will also be better characterized. This will not only help in understanding the zirconium distribution, it will also document the starting microstructure before extrusion and determine if the starting microstructure of the billet effects the ending microstructure of the extruded rod. It is known that a microstructural texture is imparted to the fuel during extrusion. The effects of this texture on U-6Zr or U-10Zr irradiation behavior is not known, but the texture should be characterized and heat treatments developed to minimize texture, if needed. As mentioned earlier, the 0.5 $\mathrm{mm}$ liner thickness is substantially thicker than is needed for an FCCI barrier, and removes fissile material from the fuel. Further study is needed to determine the minimum possible liner thickness possible. The U-10Zr extrusion went well and the trailing end was well formed; however, the leading edge showed signs of turbulent flow. This should be examined and the appropriate lengths of both header and footer determined, and overall shape (taper of the footer) that will provide more regular leading and trailing ends. Also, one of the primary benefits of extrusion is the assumed ability to extrude annular fuels. This ability needs to be verified and fully characterized in a similar manner to this study on solid fuel. 


\section{Appendix A}

\section{Force and Velocity Data}




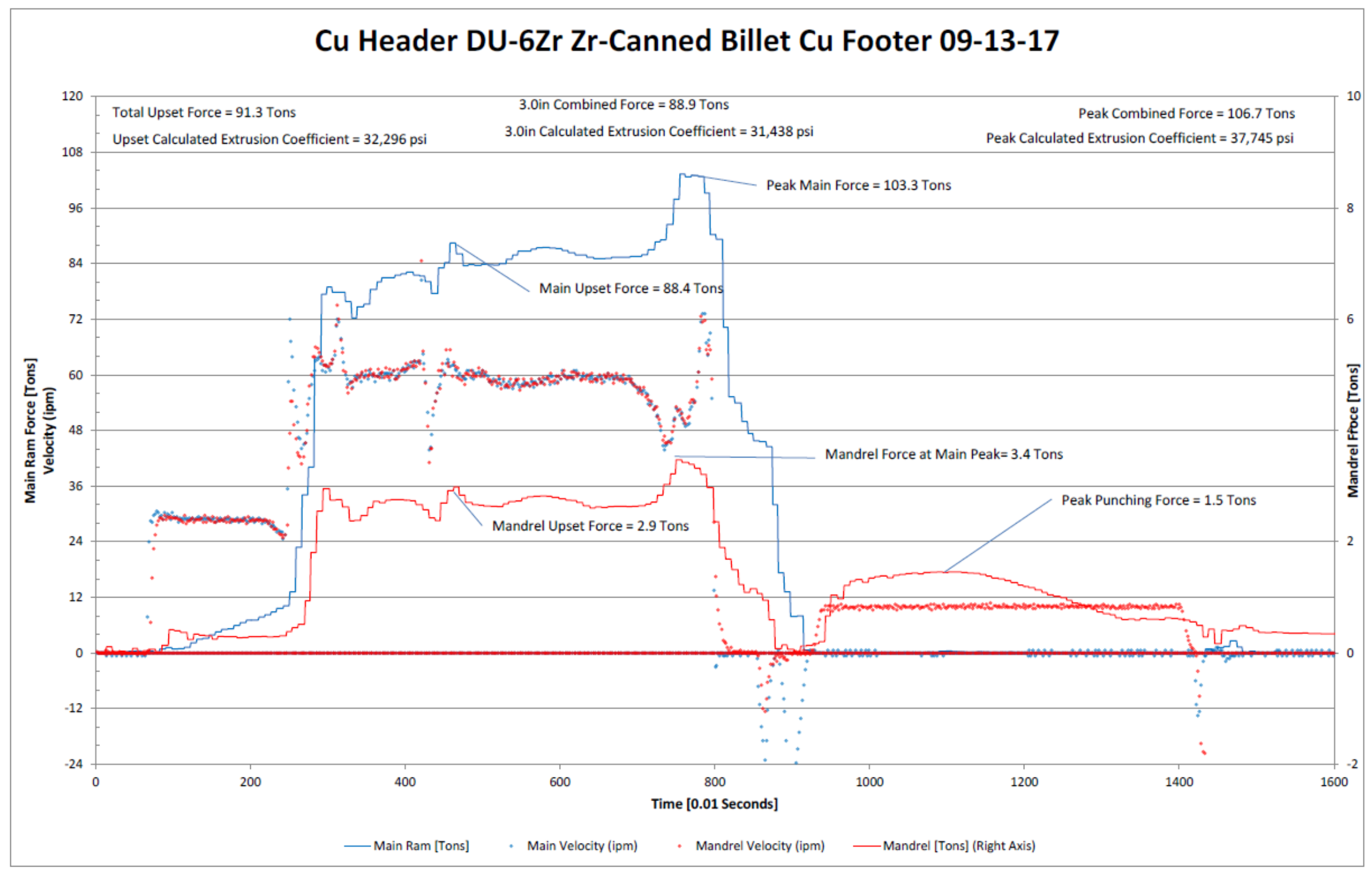




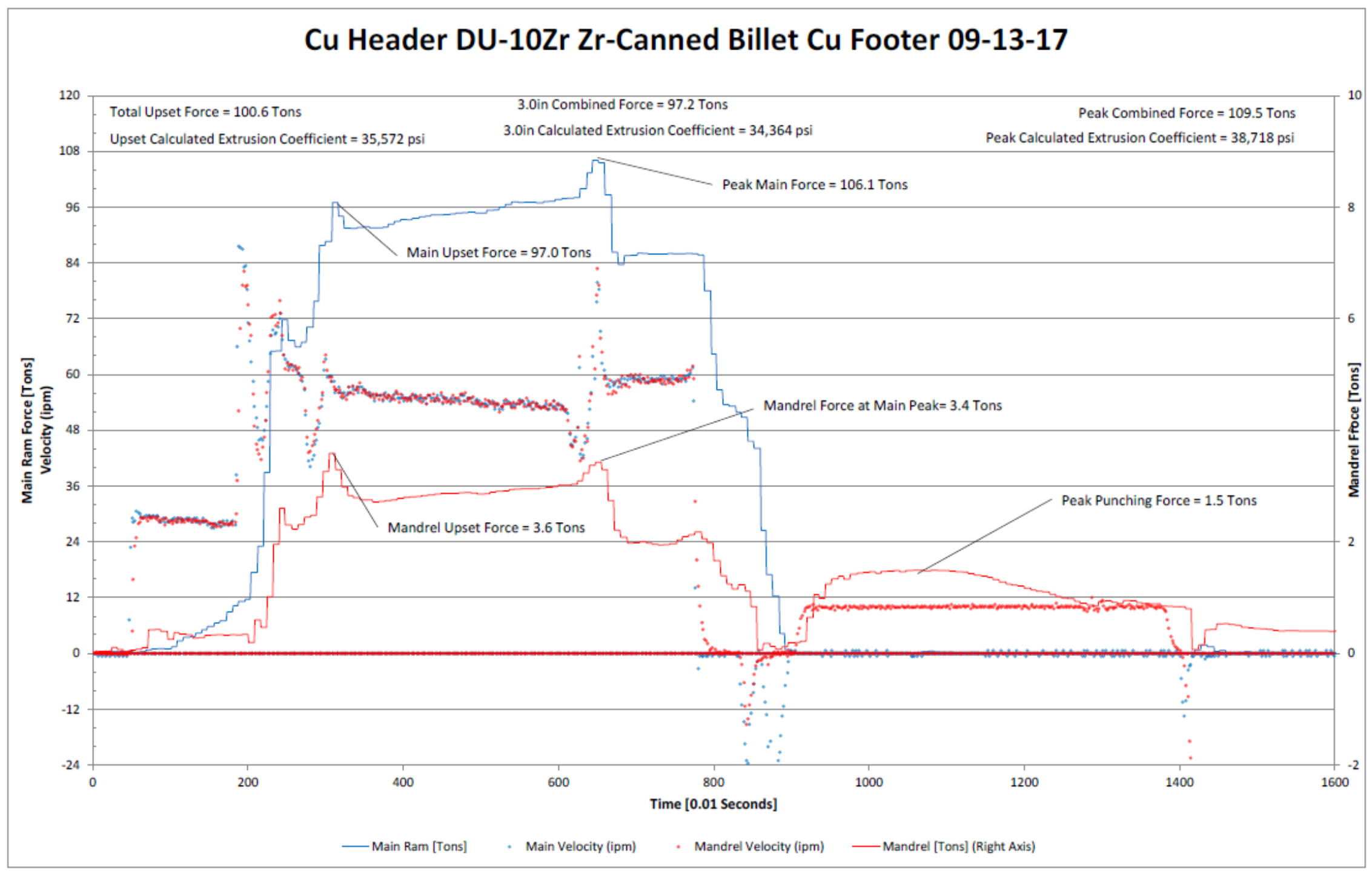

